\title{
Functional differences between two shock-induced aggressive behaviors of mice*
}

\author{
ROSS LEGRAND, GREGORY DAHL, and SUSAN MEIER \\ Saint Olaf College, Northfield, Minnesota 55057
}

\begin{abstract}
Five groups of male mice were given either isolation or grouped housing conditions or fight training as manipulations of social backgrounds prior to 5 days of shock-induced aggression under conditions resembling the rat paradigm for shock aggression. Three groups were given similar fight training but different levels of shock intensity during the shock trials. Shocks moderate in intensity as compared to very low intensity shocks produced more biting attacks and upright postures and maintained aggressiveness. Raising the shock intensity further produced fewer biting attacks, more upright postures, and a decline in aggressiveness. Biting attacks proved to be a more discriminating measure of differences created by different social backgrounds than the upright postures.
\end{abstract}

When paired mice or rats are shocked, a variety of behaviors characterized as fight or flight may be evoked. Two of these responses are commonly considered to be aggressive interactions in the literature on the relationship between pain and aggression. One is an upright "boxing" posture in which the two opponents rear on their hind legs facing each other and strike or lunge at each other. The other is a biting attack upon the flanks or back of the opponent. Grant and Mackintosh (1963) observed the performance of these behaviors by mice and rats in nonshock situations and concluded that they serve the same purposes for both species. They categorized biting attack as aggressive and the upright posture as ambivalent. It remained to be shown whether these behaviors could be similarly classified when in response to shock.

While there has been some research on the shock-induced aggressive interactions of mice (e.g., Tedeschi, Tedeschi, Mucha, Cook, Mattis, \& Fellows, 1959; Kimbrell, 1969), there has been far more exploration of the parameters of the experimental situation for rats. Manipulation of situational variables in the rat experiments, such as the floor area of the shock chamber and the intensity, duration, and frequency of shocks (e.g., Azrin, Ulrich, Hutchinson, \& Norman, 1964; Ulrich \& Azrin, 1962), has led to the development of a paradigm for rats in which the upright posture can be elicited on a large proportion of shock trials.

Legrand and Fielder (1973) shocked mice but deviated from the rat paradigm in order to demonstrate that biting attack, although less reliably provoked by shock than the upright posture, was a more sensitive measure of the effects of social roles and previous fighting experience. Dominant mice bit more often than they engaged in upright postures, whereas the upright posture was the only agonistic behavior displayed by

*This research was supported by National Science Foundation College Science Improvement Program Grant GY6887. The authors express their gratitude to Gerald Ericksen and Auke Tellegen for their assistance. submissive mice. These investigators used an aggressive strain of mice and, as compared to the rat paradigm, a relatively larger floor area in the shock chamber, a longer intertrial interval, and a range of shock intensities rather than only the high intensity most productive of the upright response. They also used a fight training technique as a manipulation of fighting experience which proved to be a powerful variable for determining the effects of social roles. One purpose of the present experiment was to use mice in a closer approximation of the rat paradigm than the study by Legrand and Fielder and to compare the effects of the fight training method with the effects of isolated or grouped housing conditions, the manipulation of social history commonly used in rat studies (e.g., Creer \& Powell, 1971a; Milligan, Powell, \& Borasio, 1973).

A second purpose was stimulated by the unreported observation by Legrand and Fielder that many aggressive mice appeared to lose their aggressiveness after subjection to the high-intensity shocks which most efficiently elicited the upright posture. Biting attack, on the other hand, has long been associated with increases in aggressiveness (e.g., Uhrich, 1940). In fact, Scott (1958) introduced a standard procedure for developing high levels of aggressiveness in mice by providing them with the opportunity for successful biting attacks. Because of the apparently conflicting results of these two procedures, the present experiment was designed to determine whether biting attacks and upright postures induced by shock are functionally equivalent. For this reason, different levels of shock were employed to elicit differentially the two behaviors.

\section{METHOD}

\section{Subjects}

The Ss were $112 \mathrm{DBA} / 2 \mathrm{~J}$ male mice obtained from the Jackson Laboratory at approximately 63 days of age. For 30 days they were housed individually in $10.2 \times 24.1 \times 12.7 \mathrm{~cm}$ metal cages with wire mesh for the floor and one side; then they 
were housed individually in $10.2 \times 29.2 \times 12.7 \mathrm{~cm}$ clear plastic breeding boxes until the start of the experiment, when they were approximately 100 days old.

\section{Training Procedure}

The Ss were assigned randomly to seven equal groups. The mice of Group 1 remained in isolation in the breeding boxes throughout the study, while the mice in Group 2 were housed in groups of four. Groups 1 and 2 represented an attempt to duplicate the isolation and group housing conditions used as the manipulation of social histories in rat studies of shock-induced aggression.

The remaining 80 mice were paired randomly and housed in the breeding boxes. They soon formed stable dominant-submissive dyads. When these roles were determined, the dominant member of each pair was provoked into a biting attack upon its helpless, dangled partner three times a day for 20 days. (For a more complete description of the method of assessing social roles and of fight training, see Legrand and Fielder.) By the end of fight training, the dominant mice attacked quickly and vigorously.

For Group 3 a dominant mouse from one breeding box was paired in the shock chamber with a dominant mouse from another box, while Group 4 consisted of similarly paired submissives. The dominant-submissive pairs of Groups 5, 6, and 7 remained paired for shock testing, but each group received a different shock intensity. For all groups, the partner in the shock chamber remained constant throughout shock testing.

Thus, Groups 1 and 2 duplicated earlier attempts to vary social histories prior to shock trials, whereas the other groups duplicated the fighting manipulation of Legrand and Fielder. Groups 5-7 were given similar fighting experience but different shock levels during testing.

\section{Apparatus and Testing Procedure}

The shock apparatus was a Lehigh Valley mouse shuttlebox. Into one half of the shuttlebox was placed a smaller shock chamber, $9.8 \times 9 \times 8.7 \mathrm{~cm}$, constructed of glass for three sides and the hinged top. The fourth side was the Plexiglas side of the shuttlebox and the floor was the steel grid bars, $.64 \mathrm{~cm}$ apart, of the shuttlebox. A Grason-Stadler shock generator delivered 100 scrambled shocks of .5-sec duration and $3 \mathrm{sec}$ apart to each pair of mice each day for 5 days.

Groups 1-5 received high-intensity shocks of $1.6 \mathrm{~mA}$. Group 6 received shocks of moderate intensity $(.3 \mathrm{~mA})$ and Group 7 received shocks of very low intensity $(.05 \mathrm{~mA})$. This last shock level elicited no detectable response to the shock.

In order to test for any changes in aggressiveness which might occur as a result of the experiences in the shock chamber, all dominant mice were assessed for the vigor of their attacks against their dangled partners on the last day of fight training and again on the day following the last day of testing. Also on the last day of training, all mice were individually allowed to explore the shock chamber without shocks for $2 \mathrm{~min}$.

The order in which the groups were run each day and the order within groups were randomized. A single $O$ recorded the biting attacks and upright postures that occurred on each shock trial. A second $\mathrm{O}$ scored on 2 of the 5 testing days, and the two Os were in agreement on $95 \%$ of the jointly recorded trials.

\section{RESULTS}

The use of experimental conditions more closely approximating those of the typical shock-aggression paradigm for rats produced rates of biting attacks and upright postures which were more similar to the rates in the rat studies than those rates obtained by Legrand and Fielder. In the latter experiment, biting or upright responses were observed on $16 \%$ of the shock trials and, of these, $86 \%$ were biting attacks. In the present experiment, biting or upright responses were observed on $43 \%$ of the shock trials and, of these, only $4 \%$ were biting attacks.

Biting attack proved to be a more sensitive measure of the manipulation of social roles than the upright posture, just as in the study by Legrand and Fielder. Of the 458 biting attacks observed, only 1 was launched by a submissive mouse, and that exception was against another submissive mouse in Group 4. In contrast, it was impossible to discern the initiator of an upright encounter.

An analysis of variance was performed on the frequencies of upright responses across days for Groups 1-5, the groups that received 1.6-mA shocks, and it revealed a difference among the groups which fell short of statistical significance $(F=2.52$, $d f=4 / 35$, $p<.10)$. A significant days effect $(F=39.82$, $\mathrm{df}=4 / 140, p<.001$ ) was due to an increase in upright responses with repeated exposure to high-intensity shocks. A similar days effect was reported by Creer and Powell (1971b) in a study of shock-induced upright responses in rats. In contrast, the tendency for the mice to engage in biting attacks decreased across days, with $88 \%$ occurring on the first 2 days of testing and none on the last 2 days.

Biting attacks for Groups 1-5 were few and not normally distributed (see Table 1), which renders the conclusions tentative. Nonparametric procedures (Siegel, 1956) were applied to these data and to the comparisons for Groups 5-7. A Kruskal-Wallis one-way analysis of variance by ranks showed that Groups $1-5$ differed significantly $(\mathrm{H}=21.77, \quad \mathrm{df}=4, \quad \mathrm{p}<.001)$. A Mann-Whitney $U$ test revealed that Group 3, the paired dominants, bit more frequently than Group 5 , the dominant-submissive pairs $(\mathrm{U}=13, \mathrm{~N}=8$ for all groups, $p<.05)$. The remaining three high-shock groups displayed virtually no biting attacks.

A Kruskal-Wallis analysis was performed on the scores for the dominant-submissive dyads of Groups 5-7, for which only shock intensities were varied, and significant differences were found for both upright postures and biting attacks $(\mathrm{H}=19.29, \quad \mathrm{df}=2, \mathrm{p}<.001$ and $\mathrm{H}=10.80, \mathrm{df}=2, \mathrm{p}<.01$, respectively). Group 7, which received $.05 \mathrm{~mA}$, showed almost no aggression and, therefore, significantly fewer upright postures and biting attacks than Group 6, which received .3-mA shocks $(U=0, p<.001$ and $U=1, p<.002$, respectively). Thus, compared to very low shocks of $.05 \mathrm{~mA}$, moderate shocks of $.3 \mathrm{~mA}$ increased the tendencies for both types of aggressive interaction. A comparison of Group 6 with Group 5, which received high-intensity shocks of - $1.6 \mathrm{~mA}$, revealed that raising the shock intensity further led to a decrease in the frequency of biting attacks but an increase in the frequency of upright postures $(U=10$, $p<.02$ and $U=0, p<.001$, respectively).

In the test for changes in aggressiveness due to shock testing, it was discovered that all eight dominant mice of 
Table 1

Upright and Biting Responses for 5 Days of Shock Testing

\begin{tabular}{|c|c|c|c|c|c|c|c|c|}
\hline \multirow{2}{*}{\multicolumn{2}{|c|}{$\begin{array}{l}\text { Shock Intensity } \\
\text { Group }\end{array}$}} & \multicolumn{5}{|c|}{$1.6 \mathrm{~mA}$} & \multirow{2}{*}{$\frac{.3 \mathrm{~mA}}{6}$} & \multirow{2}{*}{$\frac{.05 \mathrm{~mA}}{7}$} \\
\hline & & 1 & 2 & 3 & 4 & 5 & & \\
\hline Upright & $\begin{array}{l}\text { Mean } \\
\text { SD }\end{array}$ & $\begin{array}{r}232.6 \\
87.5\end{array}$ & $\begin{array}{r}290.3 \\
48.6\end{array}$ & $\begin{array}{r}300.9 \\
35.2\end{array}$ & $\begin{array}{r}306.9 \\
36.4\end{array}$ & $\begin{array}{r}293.3 \\
40.2\end{array}$ & $\begin{array}{l}13.3 \\
19.3\end{array}$ & $\begin{array}{l}0.0 \\
0.0\end{array}$ \\
\hline Biting & $\begin{array}{l}\text { Mean } \\
\text { SD }\end{array}$ & $\begin{array}{l}0.0 \\
0.0\end{array}$ & $\begin{array}{l}2.8 \\
7.8\end{array}$ & $\begin{array}{l}7.0 \\
6.9\end{array}$ & $\begin{array}{l}0.1 \\
0.4\end{array}$ & $\begin{array}{l}11.3 \\
29.1\end{array}$ & $\begin{array}{l}35.6 \\
26.8\end{array}$ & $\begin{array}{l}0.5 \\
1.4\end{array}$ \\
\hline
\end{tabular}

Group 6 attacked their dangled partners as vigorously after receiving .3-mA shocks as before, whereas of the eight dominant mice of Group 5, only three could be provoked to attack following 1.6-mA shocks. This comparative drop in aggressiveness for Group 5 as compared to Group 6 was significant at the .05 level using the Fisher exact test. It is also worth noting that all eight dominant mice of Group 7, the $.05-\mathrm{mA}$ group, also continued to attack at their previous level of aggressiveness, whereas, of the 16 mice of Group 3 which began the experiment as dominant-aggressive mice, only three remained aggressive following their subjection to high-intensity shocks.

\section{DISCUSSION}

When combined with the study by Legrand and Fielder, this experiment has shown that decreasing the floor area in the shock chamber, using only high-intensity shocks, and shortening the intertrial interval produced changes in the rate of upright agonistic postures in mice comparable to the changes in rate of a similar posture in rats when these parameters were varied in the same fashion. However, the manipulations of social experience and shock intensities in the present study revealed variations in the frequencies of upright and biting responses which may permit a clearer understanding of them.

The frequencies of upright postures did not discriminate among Groups 1-5, which were given the same high-intensity shocks during testing but different backgrounds of social experience. The nonsignificant trend of the isolated mice of Group 1 to display fewer upright postures than the grouped mice of Group 2 is in the direction of some findings in studies of shocked rats (Hutchinson, Ulrich, \& Azrin, 1965; Milligan et al, 1973), but the fact that the grouped mice were more similar than the isolates to the performance of the paired submissives of Group 4 may not support the conclusion drawn from those rat studies that isolation leads to decreases in aggressiveness. One alternative answer is that the upright response is an insensitive measure of differences in aggressiveness in this situation. Another possibility is that the absence of social interactions during the isolation period led to less agonistic interaction during shock testing.

Biting in response to shock was limited almost entirely to dominant mice throughout the study. The few biting attacks observed among Groups 1-5 do not allow sharp discriminations to be made. There was a trend for the paired dominants of Group 3 to bite more than the dominants of the dominant-submissive dyads of Group 5 and for both of these fight trained groups to bite more than the remaining high-shock groups, which did not contain trained fighters.

Groups 5-7, the trained dominant-submissive pairs given high $(1.6-\mathrm{mA})$, moderate $(.3-\mathrm{mA})$, and very low (.05-mA) shock intensities provided a better interpretation than Groups 1.5 of the relationships between upright and biting response frequencies and shock intensity. The presentation of moderate shocks to Group 6 elicited higher frequencies of both behaviors than did the very low shocks given to Group 7 . For this reason, the two patterns of response might be considered to be partially related or overlapping for mice, just as Milligan et al have suggested for rats. When the performance elicited by high shock intensity in Group 5 is compared to that of the moderate-shock Group 6, areas of independence appear, for further raising the shock level increased upright postures but decreased biting attacks.

The differences in the functional relationships of upright and biting responses to changes in shock intensity should be noted by researchers who wish to use the shock-aggression paradigm as a model of aggression. Moderate shock intensity was related to the highest frequency of biting attacks and to the maintenance of aggressiveness throughout the study, while high shock intensity was related to fewer biting attacks, the highest frequency of upright postures, and a decline in aggressiveness. Continued exposure to high-intensity shocks led to an increased frequency of the upright posture and a decreased frequency of biting attacks across the 5 days of testing. Furthermore, Legrand and Fielder demonstrated that the tendency to engage in biting attacks persists longer following shock cessation than the tendency for upright postures.

If investigators are interested in factors associated with the acquisition and maintenance of aggressive behavior patterns in mice, then the functional differences between the upright and biting behaviors demonstrated in this experiment may mean that the choice of one or the other of these behaviors as the dependent variable in a study of shock-induced aggression in mice, and perhaps also in rats, is not simply a question of experimental convenience but a matter of theoretical importance. 


\section{REFERENCES}

Azrin, N. H., Ulrich, R. E., Hutchinson, R. R., \& Norman, D. G. Effect of shock duration on shock-induced fighting. Journal of the Experimental Analysis of Behavior, 1964, 7, 9-11.

Creer, T. L., \& Powell, D. A. Effects of age and housing conditions on shock-induced aggression. Psychonomic Science, 1971a, 22, 259-261.

Creer, T. L., \& Powell, D. A. Effect of repeated shock presentations and different stimulus intensities on shock-induced aggression. Psychonomic Science, 1971b, 24, 133-134.

Grant, E. C., \& Mackintosh, J. H. A comparison of the social postures of some common laboratory rodents. Behaviour, $1963,21,246-259$

Kimbrell, G. McA. Relationship of the upright agonistic posture in the footshock situation to dominance-submission in male C57 BL/6 mice. Psychonomic Science, 1969, 16, 167-168.

Legrand, R., \& Fielder, R. Role of dominance-submission relationships in shock-induced fighting of mice. Journal of
Comparative \& Physiological Psychology, 1973, 82, 501-506. Milligan, W. L., Powell, D. A., \& Borasio, G. Sexual variables and shock-elicited aggression. Journal of Comparative Physiological Psychology, 1973, 83, 441-450.

Scott, J. P. Aggression. Chicago: University of Chicago Press. 1958.

Siegel, S. Nonparametric statistics. New York: McGraw-Hill, 1956.

Tedeschi, R. E., Tedeschi, D. H., Mucha, A., Cook, L., Mattis, P. A.4 \& Fellows, E. J. Effects of various centrally acting drugs on fighting behavior of mice. Journal of Pharmacology \& Experimental Therapeutics, 1959, 125, 28-34.

Uhrich, J. The effect of fighting experience on albino mice Ecology, 1940, 21, 100-101.

Ulrich, R. E., \& Azrin, N. H. Reflexive fighting in response to aversive stimulation. Journal of the Experimental Analysis of Behavior, 1962, 5, 511-520.

(Received for publication August 28, 1973; accepted April 10, 1974.) 